University of Wollongong

Research Online

Faculty of Engineering - Papers (Archive)

Faculty of Engineering and Information

Sciences

$1-1-2012$

\title{
Analysis of jet characteristics and structural optimization of a liquamatic fire water monitor with self-swinging mechanism
}

\author{
Guoliang Hu \\ ghu@uow.edu.au \\ Ming Long \\ East China JiaoTong University \\ Juxing Liang \\ East China JiaoTong University \\ Weihua Li \\ University of Wollongong, weihuali@uow.edu.au
}

Follow this and additional works at: https://ro.uow.edu.au/engpapers

Part of the Engineering Commons

https://ro.uow.edu.au/engpapers/4517

\section{Recommended Citation}

$\mathrm{Hu}$, Guoliang; Long, Ming; Liang, Juxing; and Li, Weihua: Analysis of jet characteristics and structural optimization of a liquamatic fire water monitor with self-swinging mechanism 2012, 805-813.

https://ro.uow.edu.au/engpapers/4517

Research Online is the open access institutional repository for the University of Wollongong. For further information contact the UOW Library: research-pubs@uow.edu.au 
Analysis of jet characteristics and structural optimization of a liquamatic fire water monitor with self-swinging mechanism

\section{Guoliang Hu, Ming Long, Juxing Liang \& Weihua Li}

The International Journal of Advanced Manufacturing Technology

ISSN 0268-3768

Volume 59

Combined 5-8

Int J Adv Manuf Technol (2012) 59:805-813

DOI 10.1007/s00170-011-3508-y

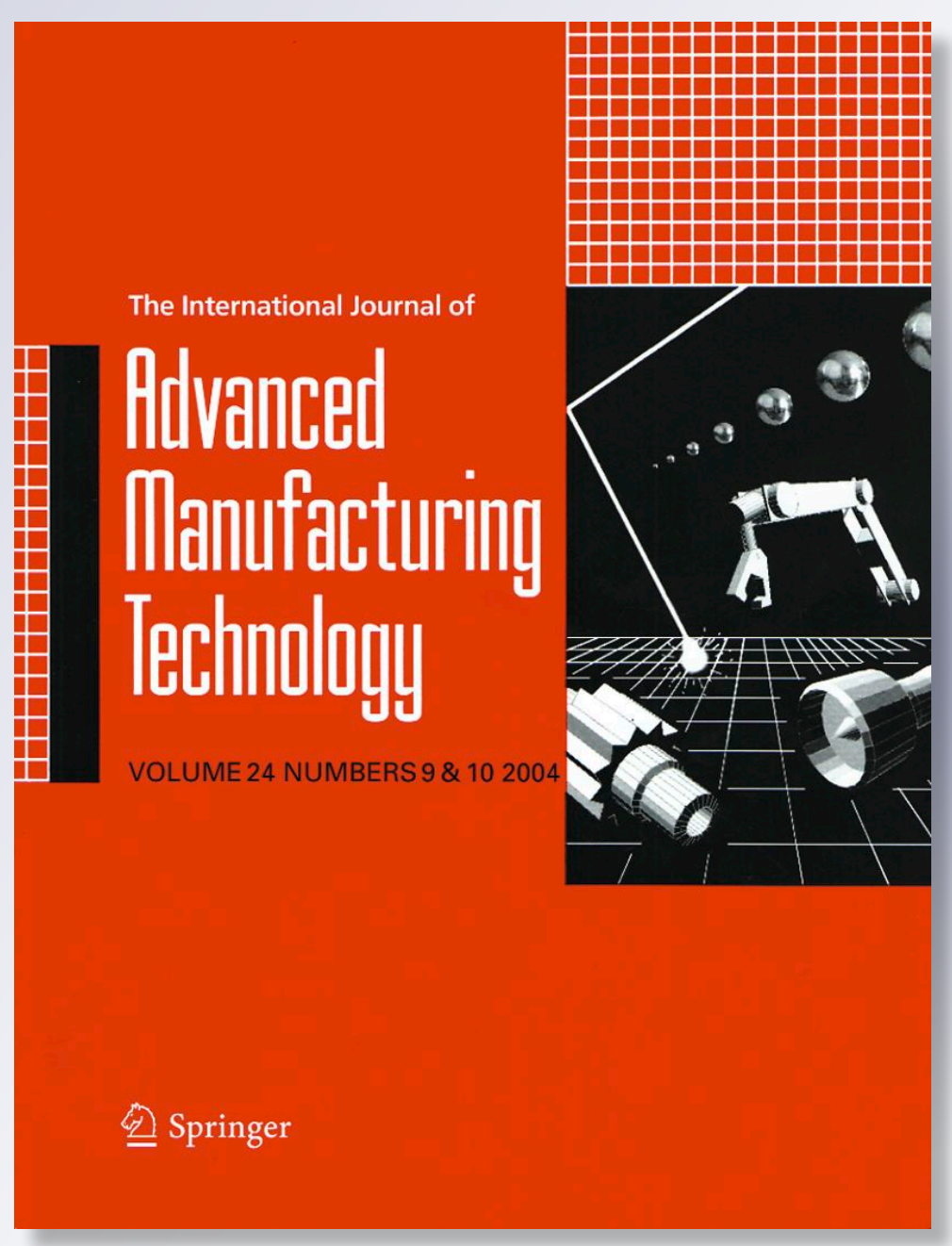

算 Springer 
Your article is protected by copyright and all rights are held exclusively by Springer-Verlag London Limited. This e-offprint is for personal use only and shall not be self-archived in electronic repositories. If you wish to selfarchive your work, please use the accepted author's version for posting to your own website or your institution's repository. You may further deposit the accepted author's version on a funder's repository at a funder's request, provided it is not made publicly available until 12 months after publication. 


\title{
Analysis of jet characteristics and structural optimization of a liquamatic fire water monitor with self-swinging mechanism
}

\author{
Guoliang Hu • Ming Long • Juxing Liang • Weihua Li
}

Received: 4 February 2011 / Accepted: 27 June 2011 / Published online: 7 August 2011

(C) Springer-Verlag London Limited 2011

\begin{abstract}
This paper presents analysis and optimization of a liquamatic fire water monitor with a novel self-swinging mechanism. The design of the self-swinging mechanism has adopted a four-bar linkage driven by an impeller. The Fluent software was used to simulate the internal flow performance of the fire water monitor. In particular, the effects of the cross-sectional shape, diameters of the monitor body, inlet water pressure, and drive set of the self-swinging mechanism on the jet characteristics were analyzed. These analyses have led to optimal structural parameters of the flow channel. A prototype of the fire ware monitor was manufactured, and the field test was performed. Both simulation analyses and experimental results are expected to provide useful good guidance for the design of other types of fire water monitor.
\end{abstract}

Keywords Liquamatic fire water monitor $\cdot$ Structural optimization · Jet characteristics · Flow field simulation

\section{Introduction}

Fire accidents increased dramatically in recent years with the development of the economy and the change of human activities. Fires not only bring serious losses, but also result

\section{G. Hu $(\bowtie) \cdot$ M. Long $\cdot$ J. Liang}

School of Mechanical and Electronical Engineering,

East China Jiaotong University,

Nanchang, Jiangxi 330013, People's Republic of China

e-mail: glhu@ecjtu.jx.cn

\section{G. $\mathrm{Hu} \cdot \mathrm{W} . \mathrm{Li}(\bowtie)$}

School of Mechanical, Materials and Mechatronic Engineering, University of Wollongong,

Wollongong NSW 2522, Australia

e-mail: weihuali@uow.edu.au in tremendous influences to the society. Thus, a variety of technologies were developed to prevent and control fires [5, 19, 22, 26]. Amongst, fire water monitor has become an important and effective firefighting equipment because of its large flow and long range. It also has the characteristics of implementation of long-range fire in the security region out of the fire radiant heat, explosion hazard, and toxic smoke situations [16-18].

In order to improve the fire extinguish efficiency to adapt to firefighting requirements in different situations, the key technology researches into fire water monitor mainly focus on two aspects. The first is intelligent control study that replaced the manual control with automatic control, which is mainly concentrating on the control algorithm and the fire extinguishing mechanism. For example, RosePehrsson et al. [14] used a four-sensor array and a probabilistic neural network to produce an early warning fire detection system, and the current alarm algorithm resulted in better overall performance than the commercial smoke detectors. Chen et al. [1] developed an automatic fire searching and suppression system with remote-controlled fire monitors for large space, and the fire searching methods was realized based on computer vision theory via one charge-coupled device camera fixed at the end of a fire monitor chamber. Jun et al. [11] investigated smoldering cotton wick and flaming diesel oil smoke plumes in thermally stratified environments in a small-scale enclosure by experimental measurements and computational fluid dynamics (CFD) simulations, and a new smoke detection method of light-section image detection was suggested to overcome the shortcomings of conventional beam-type smoke sensors and detect the early fire effectively.

The second is research on internal and external jet characteristics of fire water monitor for enhancing the jet intensity and putting out the fire quickly. Generally, the 
external jet mainly discusses the jet water movement in the atmosphere, in which the hypotheses include: (a) the water flows out from a uniform long pipe; (b) the whirlpool flow and transverse second flow in the pipe are eliminated; and (c) the outlet velocity is in an ideal state. The internal jet research was focused on enhancing the energy converting efficiency and obtaining high speed and uniform outlet velocity under the conditions of removing the non-uniform of the flow channel of the fire water monitor, which is an objective of this work.

There are many jet applications in the industries. For example, the spray nozzle of the Pelton turbine transforms potential energy into kinetic energy, and the high-speed jet pounds the bucket with one or a number of jet waters, which can drive the runner rotating to gain driving force, and the water head is above $80 \mathrm{~m}$ in general. Santolin et al. [15] numerically investigated the interaction between the jet and the bucket in Pelton turbine using a two-phase inhomogeneous model. Perrig et al. [13] did a numerical simulation and experimental study on the free surface flow in a Pelton turbine model bucket based on the two-phase homogeneous model. Zhang [23-25] expounded free surface jet from water injector and the interaction between the jet and the rotating bucket of Pelton wheel in detail. In the foundry industry, the molding sands were cleaned by the jet force of the high-pressure water jet system [4], and these techniques were also applied in the hydraulic mining and hydraulic cutting $[2,12,21]$. The jet energy was used in the high-pressure water jet system, but this energy will be dispersed out of a certain range; in other words, the jet range is very short from some millimeters to about $10 \mathrm{~m}$ in this system, and the flow rates is below $10 \mathrm{~L} / \mathrm{s}$. This is the essential difference between the high-pressure water jet and the fire water monitor jet, but it can provide some guidance for the research of jet characteristics of the fire water monitor. The water jet was also used in the sprinkler irrigation system in the

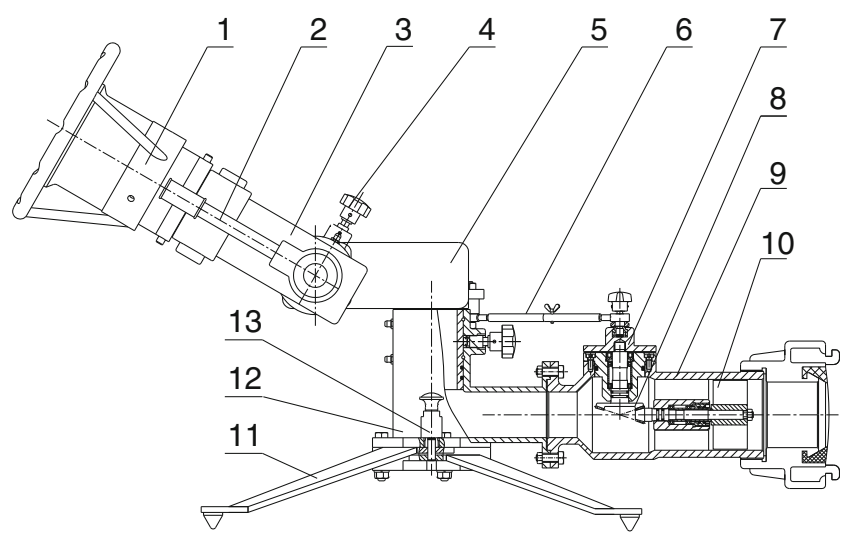

Fig. 1 Structure diagram of the liquamatic fire water monitor. 1 monitor head, 2 handle operation device, 3 outlet pipe, 4 location and locking device, 5 inlet pipe, 6 self-swinging arm, 7 circular driving plate, 8 bevel gear, 9 driven shell, 10 impeller, 11 monitor legs, 12 monitor base, 13 support legs and locking device

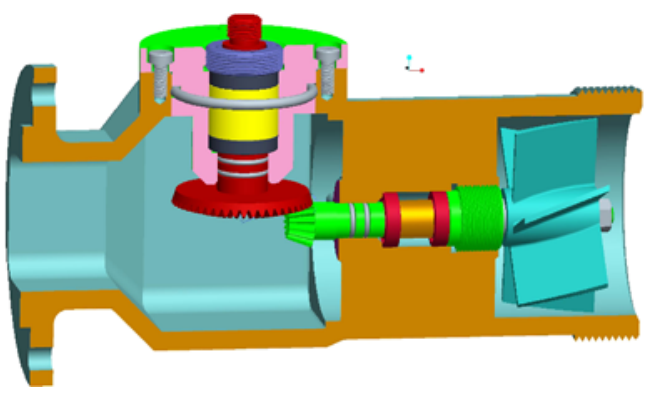

Fig. 2 Structural diagram of the self-swinging mechanism

agriculture $[3,20]$. This jet has some similarities with the jet of fire water monitor, that is, both of them have a requirement of jet range. However, agriculture sprinklings are more emphasizing the sprinkler irrigation uniformity and the water droplet diameter; the jet range is not the only indexes. So, the spray jet of the irrigator is a dispersed spray compared with the jet of the fire water monitor.

$\mathrm{Hu}$ et al. [6-8] designed a fixed fire water monitor, the influence of the flow structure affecting the internal flow's turbulence and outlet velocity was obtained by simulation and experiment. At the same time, the spray jet and direct jet nozzle used for this fixed fire water monitor was also designed. Flow simulation of the nozzle was completed using fluent kits. Hu et al. [9, 10] also designed a liquamatic fire water monitor with valve-controlled cylinder system. The back and forth movement of the monitor head is controlled by the valve-controlled cylinder system. The hydraulic performance simulation of the liquamatic fire water monitor was completed in the Fluent kits; the simulation results show that the outlet velocity is feasible. The modeling and simulation analysis were carried out for the valve-controlled cylinder system using AMESim software, the simulation results indicate that this system can self-swing in a particular frequency, and the selfswinging frequency is increasing with the inlet water pressure increasing.

The aim of this work is to design a new liquamatic fire water monitor by systematically investigating the relation-

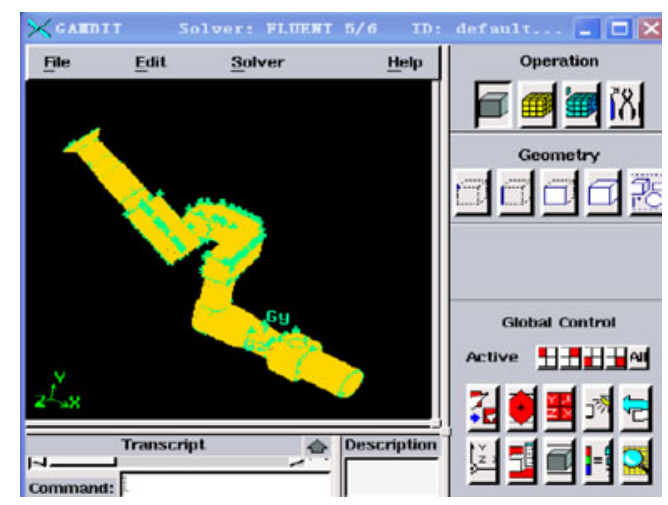

Fig.3 Meshing diagram of liquamatic fire water monitor 
Fig. 4 Flow channel model

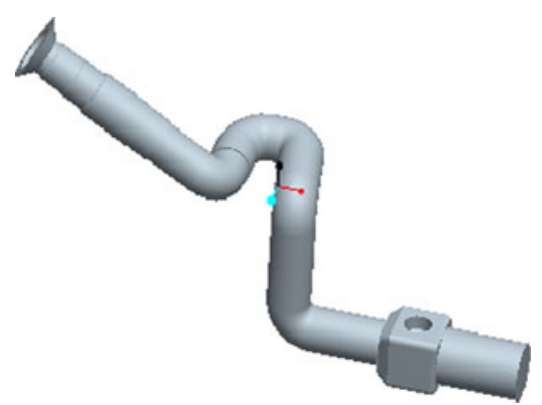

a) circular shape

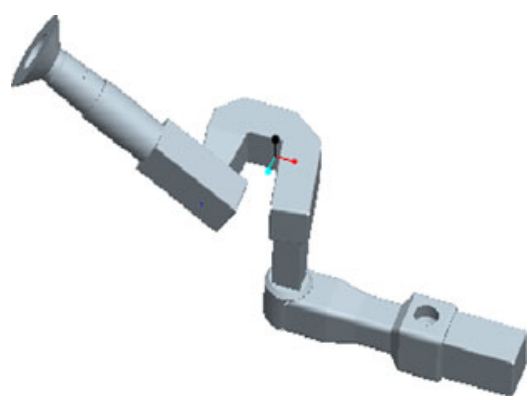

b) square shape ships between the structural parameters of the flow channel and the jet characteristics of the liquamatic fire water monitor. The simulation analysis will lead to an optimal design of the fire water monitor.

\section{Structural design of liquamatic fire water monitor with self-swinging mechanism}

\subsection{Structural design}

The liquamatic fire water monitor was mainly composed of monitor legs, monitor base, monitor body, and monitor head. The schematic of the overall structure of liquamatic fire water monitor is shown in Fig. 1. It is supported by four turning and folding monitor legs, which is convenient for transportation and placement. The spoke center of the monitor base supports the axis of bevel gear, which connects with an impeller. When the pressure water enters the monitor base interior, it can produce momentum to propel the impeller turning. The bevel gear is connected to circular driving plate of the self-swinging mechanism. So, horizontal movement will transfer to the vertical direction.
The circular driving plate has a sliding slot, which houses a slider. This driving plate is equivalent to an eccentric wheel with an adjustable arm, which can adjust the swing range of monitor head. When the slider is positioned, it can be locked by the self-swinging locking device. The locking tappet is attached to two connecting rods, which form the self-swinging mechanism through a butterfly bolt. The monitor body is a main part of the flow channel including inlet pipe and outlet pipe. The monitor head is also an important part and includes several important components, such as rectifier, nozzle, and so on. It is the ultimate part to achieve energy transformation and jet pattern. The elevation angle of the monitor head is located and locked by the location and locking device. The opening of nozzle can be adjusted by a handle operation device, which can determine jet pattern.

\subsection{Working principle of the self-swinging mechanism}

The structural diagram of the self-swinging mechanism is shown in Fig. 2. It was composed of a connecting rod, a slide block locating device and a circular driving plate. The bevel gear can get the torque from pressure water and make the direction change as it works.
Fig. 5 Velocity flow of circular flow channel

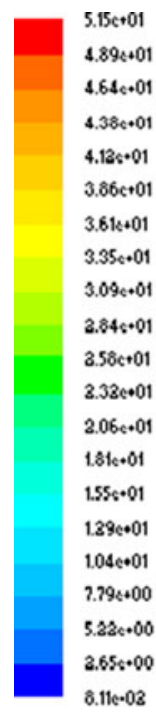

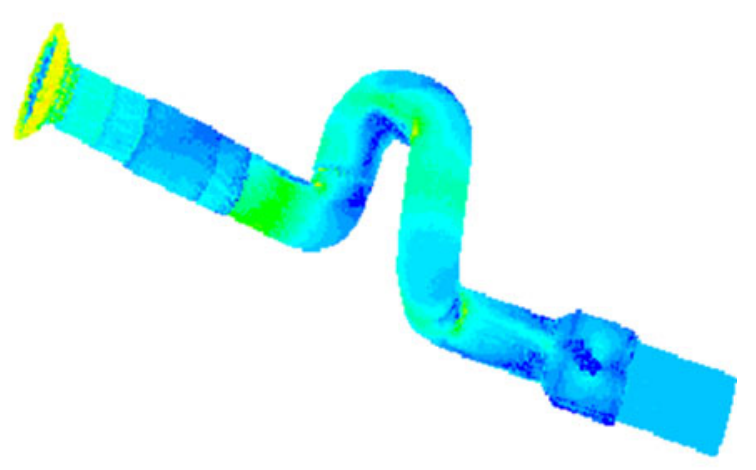


In the device, the four-bar linkage mechanism is formed by the circular driving plate, the slide block, the monitor head, and the connecting rod. Based on the four-bar linkage principle, the monitor head can swing from the angle of $-30^{\circ}$ to the angle of $+30^{\circ}$ in horizontal direction, and pressure water also can be spurted out from monitor head with a high speed. So swinging jet will be formed to put out wide-range fire.

\section{Modeling analysis of the liquamatic fire water monitor}

Fluent software, as one of the general CFD software, is used to simulate complex flow, ranging from incompressible fluid to highly compressible fluid. Various methods for solution and multi-grid accelerating convergence method are adopted to simulate the flow field. In this study, the internal flows of different structural parameters are simulated, and the influences of these parameters on jet characteristics are obtained.

\subsection{Governing equation and RNG K- $\varepsilon$ turbulence model}

The liquamatic fire water monitor has some curved flows, such as outlet pipe and inlet pipe. These curved flows often accompany extremely complex flow, and they cause the total pressures and energy losses, such as forming separation, secondary flow, et al. In order to adapt to jet in the big bend pipe, RNG K- $\varepsilon$ turbulence model is adopted to make the equation closed.

Continuity equation of fluid in coordinate system is:

$\frac{\partial \rho}{\partial t}+\frac{\partial}{\partial x_{i}}\left(\rho u_{i}\right)=0$

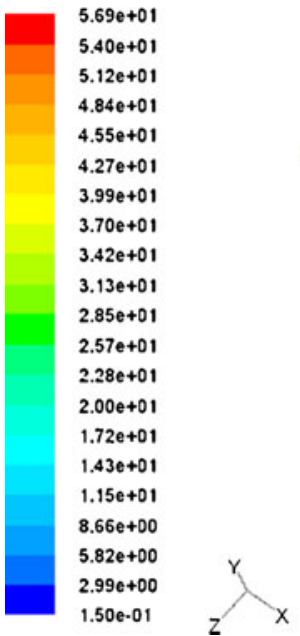

Fig. 6 Velocity flow of square flow channel

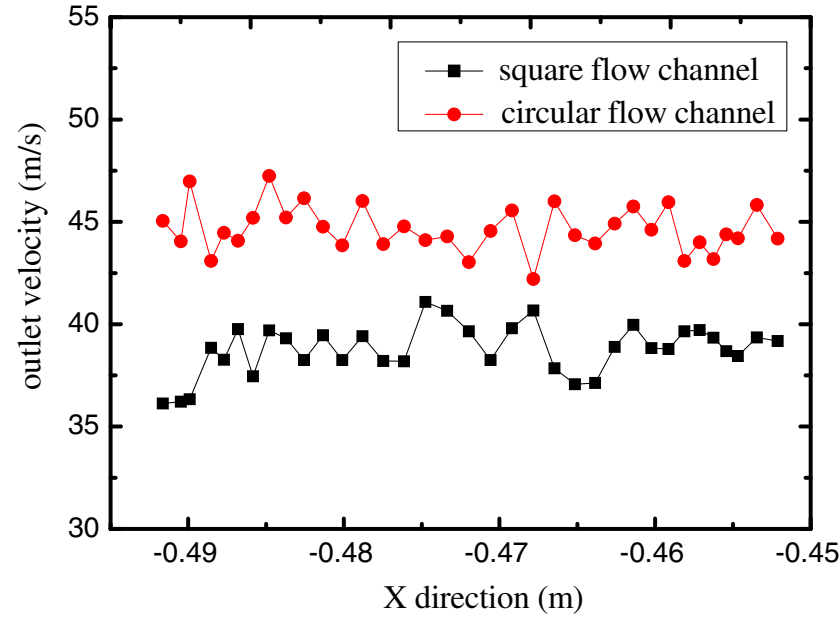

Fig. 7 Outlet velocity under different cross-sectional shapes

Momentum equation is:

$\frac{\partial \rho u_{\mathrm{i}}}{\partial t}+\frac{\partial\left(\rho u_{\mathrm{i}} u_{\mathrm{j}}\right)}{\partial x_{\mathrm{j}}}=-\frac{\partial p}{\partial x_{\mathrm{i}}}+\frac{\partial}{\partial x_{\mathrm{j}}}\left(\mu \frac{\partial u_{\mathrm{i}}}{\partial x_{\mathrm{j}}}-\rho \overline{u_{\mathrm{i}} u_{\mathrm{j}}}\right)+S_{\mathrm{i}}$

where $\rho$ is the water density, $u_{\mathrm{i}}, u_{\mathrm{j}}$ is the velocity vector respectively, $S_{\mathrm{i}}$ is the append coefficient that considering the mean velocity change and density pulsing influence is omitted.

In the RNG K- $\varepsilon$ turbulence model, small-scale effect is reflected by large scale and viscosity amendment, and it is systematically removed from governing equation. The $k$ equation and $\varepsilon$ equation take the following form:

$\frac{\partial(\rho k)}{\partial t}+\frac{\partial\left(\rho k u_{\mathrm{i}}\right)}{\partial x_{\mathrm{i}}}=\frac{\partial}{\partial x_{\mathrm{j}}}\left[\alpha_{\mathrm{k}} \mu_{\mathrm{eff}} \frac{\partial k}{\partial x_{\mathrm{j}}}\right]+G_{\mathrm{k}}-\rho \varepsilon$

$\frac{\partial(\rho \varepsilon)}{\partial t}+\frac{\partial\left(\rho \varepsilon u_{\mathrm{i}}\right)}{\partial x_{\mathrm{i}}}=\frac{\partial}{\partial x_{\mathrm{j}}}\left[\alpha_{\varepsilon} \mu_{\mathrm{eff}} \frac{\partial \varepsilon}{\partial x_{\mathrm{j}}}\right]+\frac{C_{1 \varepsilon}{ }^{*}}{k} G_{\mathrm{k}}-C_{2 \varepsilon} \rho \frac{\varepsilon^{2}}{k}$

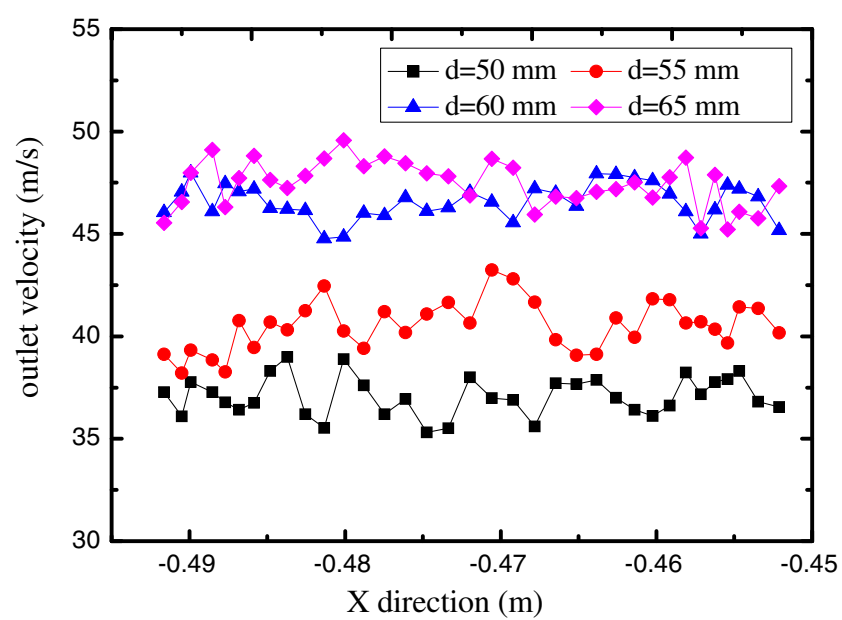

Fig. 8 Outlet velocity under different monitor body diameters 
where $C_{\mu}=0.0845, \alpha_{\mathrm{k}}=\alpha_{\varepsilon}=1.39, C_{1 \varepsilon}=1.42, C_{2 \varepsilon}=1.68, \eta_{0}=$ $4.377, \beta=0.012$.

$G_{\mathrm{k}}$ is an auxiliary coefficient of the turbulence kinetic energy induced by the mean velocity gradient. It can be expressed as

$G_{\mathrm{k}}=\mu_{\mathrm{t}}\left(\frac{\partial u_{\mathrm{i}}}{\partial x_{\mathrm{j}}}+\frac{\partial u_{\mathrm{j}}}{\partial x_{\mathrm{i}}}\right) \frac{\partial u_{\mathrm{i}}}{\partial x_{\mathrm{j}}}$

$E_{\mathrm{ij}}$ is the dependent time shear rate, given by

$E_{\mathrm{ij}}=\frac{1}{2}\left(\frac{\partial u_{\mathrm{i}}}{\partial x_{\mathrm{j}}}+\frac{\partial u_{\mathrm{j}}}{\partial x_{\mathrm{i}}}\right)$

Fig. 9 Velocity flow in the bent pipe $\mu_{\mathrm{t}}$ is turbulent viscosity, expressed as

$\mu_{\mathrm{t}}=\rho C_{\mu} \frac{k^{2}}{\varepsilon}$

and $\mu_{\mathrm{eff}}=\mu+\mu_{\mathrm{t} ;} \eta=\left(2 E_{\mathrm{ij}} \cdot E_{\mathrm{ij}}\right)^{1 / 2} \frac{k}{\varepsilon} ; C_{1 \varepsilon}^{*}=C_{1 \varepsilon}-\frac{\eta\left(1-\eta / \eta_{0}\right)}{1+\beta \eta^{3}}$

\subsection{Meshing}

The geometrical model was firstly established using Pro/E software. The complete model was then imported to the Gambit tool of the Fluent software to generate grid. Modeling and meshing time can be reduced using Gambit.
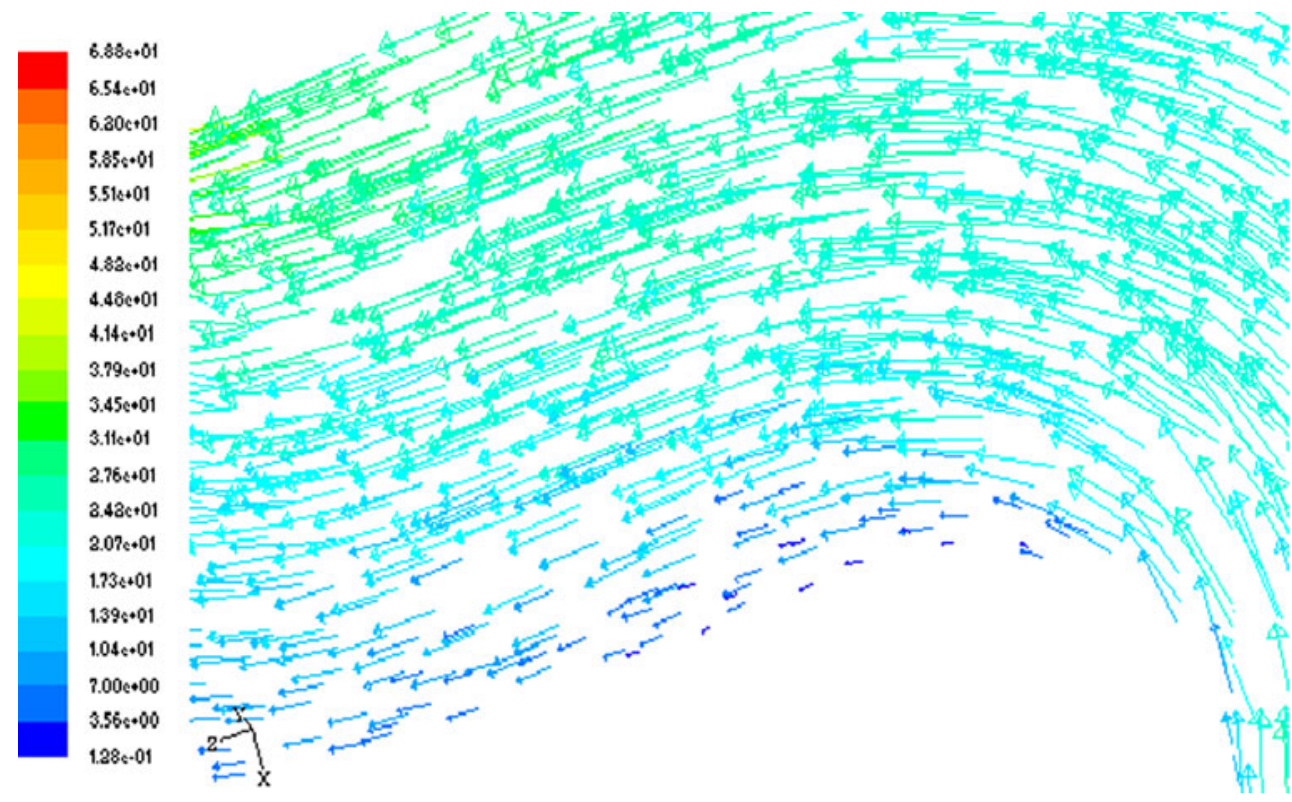

a) $d=60 \mathrm{~mm}$
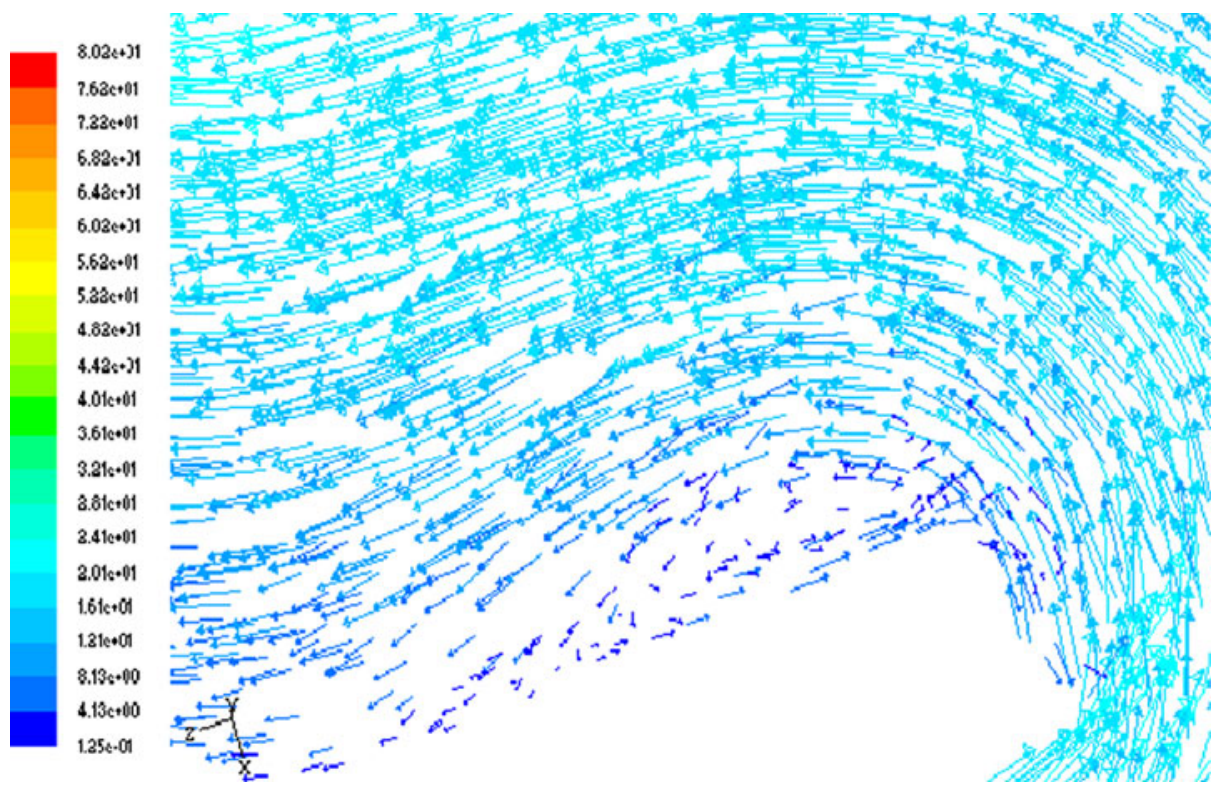

b) $d=65 \mathrm{~mm}$ 
In order to improve accuracy, the tetrahedral grid was mainly used. In some special positions, such as in the bend pipe and the outlet of the nozzle, hexahedral, tapered, and wedge grid units were also adopted. The meshing diagram is shown in Fig. 3.

\subsection{Boundary conditions}

According to the specific requirements of the liquamatic fire water monitor, the inlet water pressure is fixed. So, the boundary condition of inlet was set as pressure inlet, and the boundary condition of outlet was set to the pressure outlet. The weight of solid wall uses a non-slip condition, and the velocity uses near-wall function in fluid of nearwall flow surface.

The pressure boundary was input as the total pressure. For the incompressible flow, total pressure, static pressure, and velocity have relationships in the following formula.

$p_{0}=p_{\mathrm{s}}+\frac{1}{2} \rho v^{2}$

where $p_{0}$ is total pressure, $p_{\mathrm{s}}$ is static pressure, $\rho$ is density, and $\nu$ is fluid velocity.

\subsection{Solving algorithm}

There are three solving algorithms including egregated, coupled implicit, and coupled explicit. Egregated is provided for incompressible fluid or Mach number compressible fluid. The coupled solver is provided for high compressible flow, and it takes a long time to iterative. Due to the actual flow and iterated time, egregated is adopted.

\section{Simulation analysis of structural parameters on jet characteristics}

\subsection{Effect of cross-sectional shape of the body on outlet velocity}

The cross-sectional shape of the monitor body has great influences on the jet characteristics. As different crosssectional shape causes different energy loss, velocity flows also appear different change in the different cross-sectional shape. Here, two typical cross-section structures, including the circular shape and the square shape, as shown in Fig. $4 a, b$, were analyzed, and the jet performances with these two shapes were compared.

Figures 5 and 6 show the velocity flow simulation under these two cross-sectional shapes of the monitor body. Each bent pipe appears certain turbulence phenomena, where the fluid velocity in these areas varies dramatically. This indicates that the energy losses increase in the bent pipe, which has an adverse effect on steady flow field. The comparison indicates that the turbulence phenomena in circular flow channel are lower than that in square flow channel. When pressure water flows through monitor head, velocity flow in the circular flow channel is more smoothly than that in the square flow channel. Thus, the circular flow channel can well reduce the degree of turbulence and favors the increment of the monitor jet.

Figure 7 shows the outlet velocity under both square and circular flow channels. The values of the $x$-axis represent the projections of the distance between the radial outlet velocity and the jet center of the spray nozzle in the $x$ direction. It can be seen that the outlet velocity in the circular flow channel can reach $45 \mathrm{~m} / \mathrm{s}$, while in the square channel, it is about $40 \mathrm{~m} / \mathrm{s}$. This has further proven that circular flow channel is able to reduce water resistance, which is favorable for jet.

\subsection{Effect of the monitor body diameter on the outlet velocity}

The outlet velocity under four typical monitor body diameters of 50, 55, 60, and $65 \mathrm{~mm}$, is shown in Fig. 8 . The outlet velocity shows an obvious increase when the body diameter increases from 50 to $60 \mathrm{~mm}$. However, when the diameter further increases to $65 \mathrm{~mm}$, the outlet velocity has almost no change. It is also noted that the energy losses increase with the body diameter in fluid transmission process, which means that the channel with a diameter of $65 \mathrm{~mm}$ has the highest energy loss. When the diameter reaches a certain value, the outlet velocity will be affected by energy losses and the degree of turbulence.

Figure 9 shows the velocity flow simulation at diameters of 60 and $65 \mathrm{~mm}$ in the bent pipe. The velocity flow keeps in a steady state at the diameter of $60 \mathrm{~mm}$ and is not seriously affected by uneven flow distribution, leakage, and

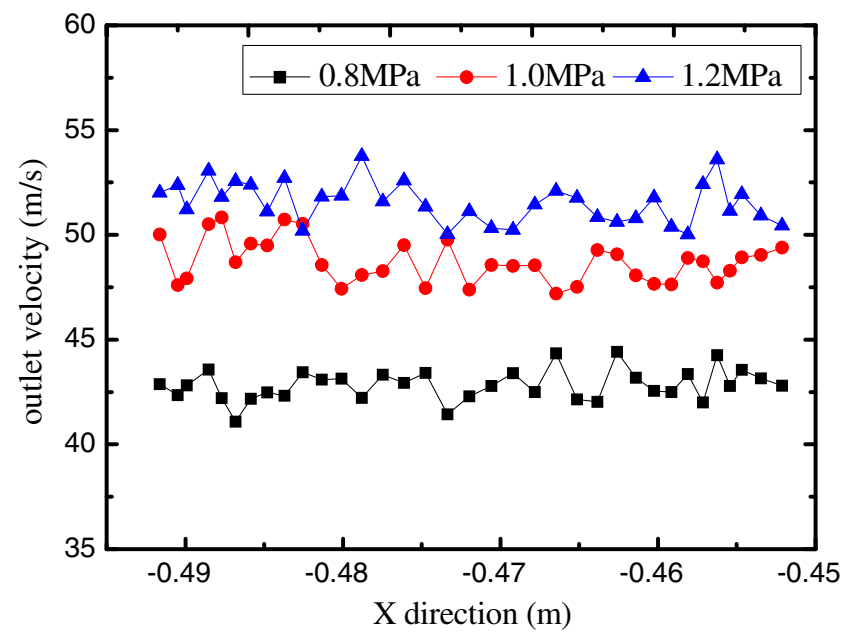

Fig. 10 Outlet velocity at a different inlet water pressure 
Fig. 11 3D model of two typical types of impeller

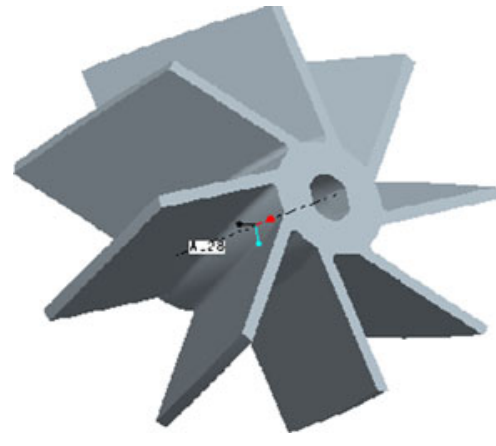

a) right-angle type impeller

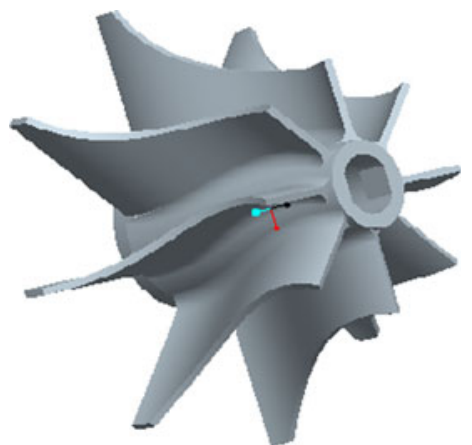

b) circular arc type impeller turbulence. When the diameter of the monitor body is $65 \mathrm{~mm}$, disturbances, agitation, cavitations, and whirlpool wake appeared in the bent pipe. This is because that when the velocity and direction changed, the particles hit each other, the energy loss at a certain degree.

\subsection{Effect of inlet water pressure on the outlet velocity}

The outlet velocity under three inlet water pressures of 0.8 , 1.0, and 1.2 MPa, is shown in Fig. 10. Obviously, the outlet velocity increases steadily with the increment of the inlet water pressure. However, larger inlet water pressure results in larger stress of the fire water monitor, which has an effect on steady operation of the fire water monitor. Currently, big recoil and easy sliding of the liquamatic fire water monitor are common problems, so over stress is unfavorable for monitor work. When the inlet water pressure increases from 0.8 to $1.0 \mathrm{MPa}$, the outlet velocity has a sharp increase from 42 to $50 \mathrm{~m} / \mathrm{s}$. But the inlet water pressure is $1.2 \mathrm{MPa}$; the outlet velocity has only a slight increase. Further study indicated that the increment degree of outlet velocity will decrease when the inlet water pressure reaches a certain value. The increment of the outlet velocity also increases the flow channel pressure, as well as unstable working.

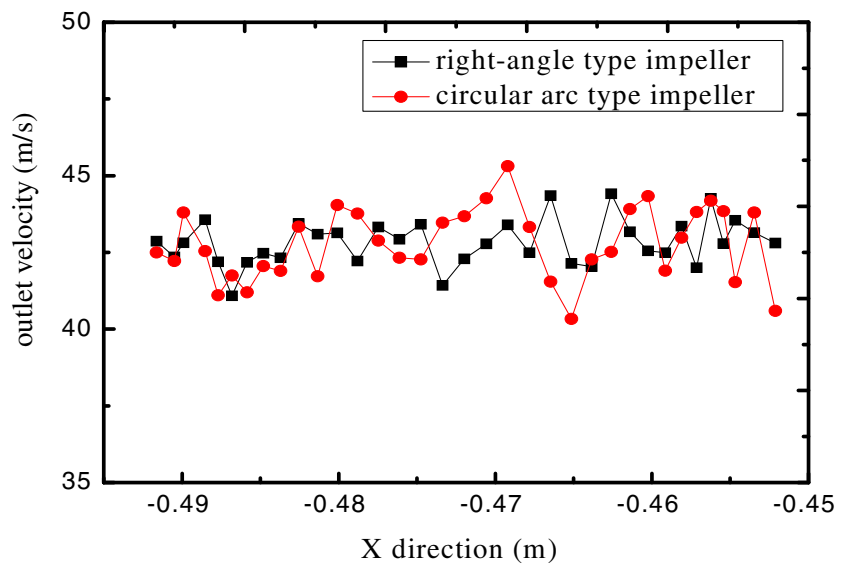

Fig. 12 Outlet velocity at different shapes of the impeller

\subsection{Effect of self-swinging drive set on the outlet velocity}

The impeller plays an important role in the liquamatic fire water monitor with self-swinging mechanism. It is driven by pressure water and produces momentum to propel bevel gear such that the horizontal movement transfers to the vertical direction. The momentum makes circular driving plate rotate, which can adjust the swing range of monitor head. In this study, two impeller types, the right-angle type impeller and the circular-arc type impeller, as shown in Fig. 11, were adopted to study the effect of the impeller type on the jet performances.

Figure 12 shows the outlet velocities for these two types of impellers. It can be seen from the figure that the two shapes of the impellers have little influence on the outlet velocity. This fluid may appear as turbulent under the impact of a fixed inlet water pressure, but unstable flow will collide with the wall in the process of flowing, transverse circulation, and turbulent fluid will gradually reduce or disappear to reach a stable situation. As the cost

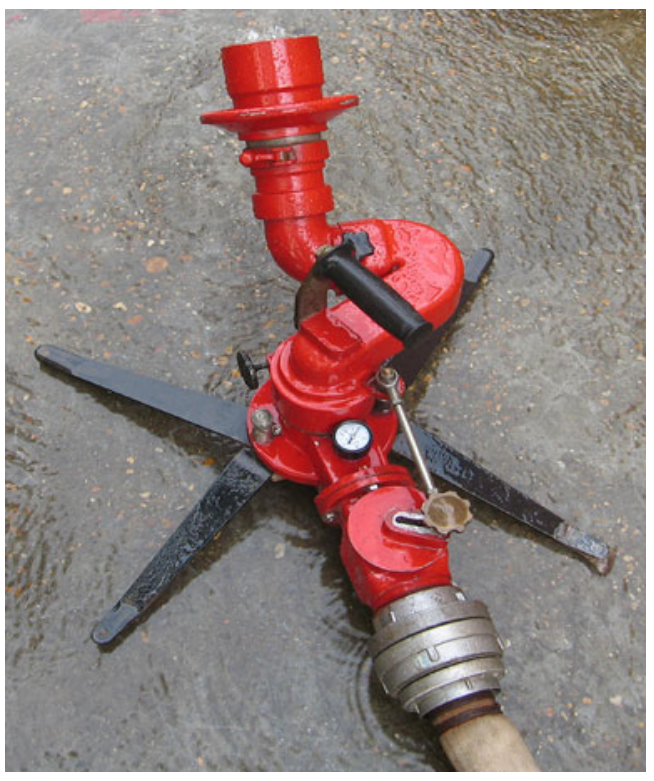

Fig. 13 The prototype of the liquamatic fire water monitor 


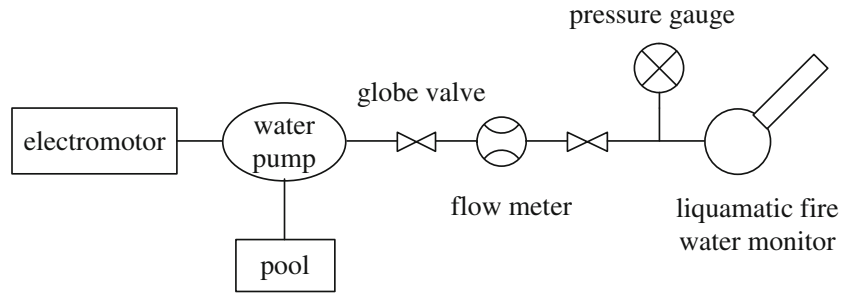

Fig. 14 The sketch of the experimental system

of the right-angle type impeller is cheaper than that of the circular-arc type impeller, the right-angle impeller will be selected in our prototype.

\section{The optimal structural parameters of flow channel}

The above simulation discussed the effects of crosssectional shapes, diameters of the monitor body, and inlet water pressure on the jet characteristics. On one hand, drive set effects on outlet velocity are small and have little influence on jet performances. On the other hand, structural parameters have significant influences on the jet performances, which should be considered for its influences on the recoil of the fire water monitor.

Taking into account all above factors, an optimal configuration, as well as other parameters of the flow channel, was recommended. That is, a circular flow channel, inlet water pressure of 1.0 $\mathrm{MPa}$, monitor body diameter of $60 \mathrm{~mm}$, and right-angle type impeller.

\section{Prototyping and fields test}

The prototype of the liquamatic fire water monitor is shown in Fig. 13. For the convenience of the movement in the firefighting, the materials of the monitor are all aluminum alloy. Some basic components, such as inlet pipe, outlet pipe, monitor base, driven shell, and monitor head are all manufactured by foundry. During assembly, nozzle must be

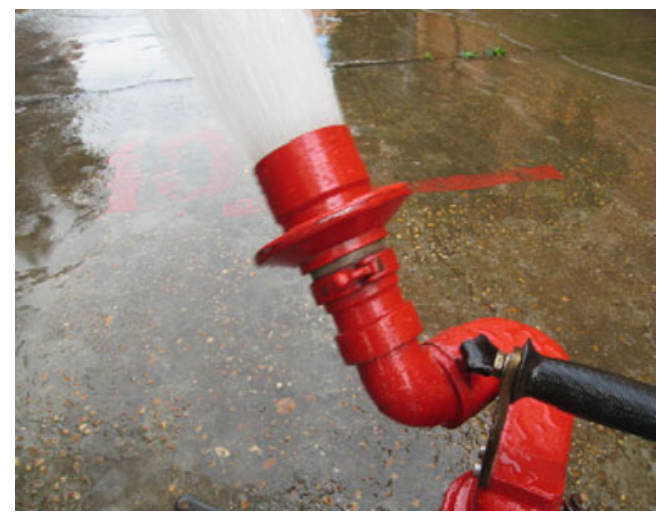

Fig. 15 Jet diagram at field
Table 1 Jet range in different inlet water pressure

\begin{tabular}{llll}
\hline Inlet water pressure [MPa] & 0.8 & 1.0 & 1.2 \\
Jet range $[\mathrm{m}]$ & 57 & 62 & 68 \\
\hline
\end{tabular}

properly connected; mismatched or damaged threads may cause nozzle to leak or uncouple under pressure and could cause injury. To protect against sliding, the monitor legs are locked in position with all leg spikes in contact with the ground.

The schematic of the experimental system for verifying the fire water monitor is shown in Fig. 14. The system contains an electromotor, a water pump, a flow meter, a pressure gauge, and the liquamatic fire water monitor. The experiment was conducted on a flat site with the wind speed below $3 \mathrm{~m} / \mathrm{s}$. The elevation angle of the liquamatic fire water monitor was set from $30^{\circ}$ to $75^{\circ}$. Figure 15 shows the pictures of the field tests. The field test video is also available.

The relationship between the inlet water pressure and the jet range is shown in Table 1. The elevation angle of the fire water monitor was set to $30^{\circ}$ in this experiment. For three typical pressures of $0.8,1.0$, and $1.2 \mathrm{MPa}$, their jet ranges are 57, 62, and $68 \mathrm{~m}$, respectively, which all satisfied the jet requirements of the designed monitor. For the largest pressure of 1.2 $\mathrm{MPa}$, we had to add an auxiliary hawse to fix the fire water monitor to prevent its sliding. Other two lower pressures of 0.8 and $1.0 \mathrm{MPa}$ do not need such auxiliary components, which are more stable and also were well verified by the simulation.

The relationship between the elevation angle and the jet range is shown in Table 2. The inlet water pressure was set as $1.0 \mathrm{MPa}$ in this experiment. For four typical elevation angles of $30^{\circ}, 45^{\circ}, 60^{\circ}$, and $75^{\circ}$, their jet ranges are 62,60 , 49 , and $34 \mathrm{~m}$, respectively, which all satisfied the jet requirements of the designed monitor expect for the elevation angle of $75^{\circ}$. The jet range in the elevation angle of $30^{\circ}$ is longer than the elevation angle of $45^{\circ}$ due to the self-gravitation of the jet water. However, the jet height in the elevation angle of $75^{\circ}$ is the highest though the jet range is the shortest, which is favorable for the high building's firefighting.

\section{Conclusions}

A novel liquamatic fire water monitor with self-swinging mechanism was analyzed, optimized, and tested. The

Table 2 Jet range in different elevation angle

\begin{tabular}{lllll}
\hline Elevation angle $\left[{ }^{\circ}\right]$ & 30 & 45 & 60 & 75 \\
Jet range $[\mathrm{m}]$ & 62 & 60 & 49 & 34 \\
\hline
\end{tabular}


prototype has a compact structure and easy to operate. Its design has met the demands in firefighting. The simulation analysis was conducted using Fluent software. The effects of structural parameters on the jet performances were summarized, which resulted in an optimal design. That is, a circular flow channel, if inlet water pressure of 1.0 MPa, monitor body diameter of $60 \mathrm{~mm}$, and right-angle type impeller were selected. The design was prototyped and its performances were field tested. The experimental results have well verified the simulation analysis.

Acknowledgments This study was supported by the National Natural Science Foundation of China (no. 50865004), Educational Commission of Jiangxi Province of China (no. GJJ11428), and the University of Wollongong UIC scheme.

\section{References}

1. Chen T, Yuan HY, Su GF, Fan WC (2004) An automatic fire searching and suppression system for large spaces. Fire Saf J 39 (4):297-307

2. Cui LL, An LQ, Gong WL, Jiang HJ (2007) A novel process for preparation of ultra-clean micronized coal by high pressure water jet comminution technique. Fuel 86(5-6):750-757

3. De Wrachien D, Lorenzini G (2006) Modelling jet flow and losses in sprinkler irrigation overview and perspective of a new approach. Biosyst Eng 94(2):297-304

4. Gao J, Zhang R, Cao GQ, Zhang GM (2009) The model analysis of molding sand's removal and mechanism research using high pressure water-jet technique. Appl Mech Mater 16-19:1127-1132

5. Guo TN, Fu ZM (2007) The fire situation and progress in fire safety science and technology in China. Fire Saf J 42(3):171-182

6. Hu GL, Chen WG (2010) Hydraulic performance research of a fixed fire water monitor. Adv Mater Res 97-101:2792-2796

7. Hu GL, Chen WG, Gao ZG (2010) Flow analysis of spray jet and direct jet nozzle for fire water monitor. Adv Mater Res 139141:913-916

8. Hu GL, Chen WG, Zhou XJ (2009) Design and simulation analyses of fixed fire water monitor. Proceedings of the Seventh International Conference on Fluid Power Transmission and Control, ICFP'2009, pp 720-723.

9. Hu GL, Gao ZG (2010) Design and numerical simulation of the liquamatic fire water monitor with vavle-controlled cylinder device. The International Workshop on Mechanic Automation and Control Engineering, MACE'2010, pp 2524-2527

10. Hu GL, Gao ZG (2011) Dynamic characteristics research of selfswinging control system with valve-controlled cylinder device for liquamatic fire water monitor. Appl Mech Mater 44-47:14271431

11. Jun F, Ji J, Yuan HY, Zhang YM (2006) Early fire smoke movements and detection in high large volume spaces. Build Environ 41(11):1482-1493

12. Kulekci MK (2002) Processes and apparatus developments in industrial waterjet applications. Int $\mathrm{J}$ Mach Tool Manufact 42 (12):1297-1306

13. Perrig A, Avellan F, Kueny JL, Farhat M, Parkinson E (2006) Flow in a Pelton turbine bucket: numerical and experimental investigations. Journal of Fluid Engineering 128(2):350-358

14. Rose-Pehrsson SL, Hart SJ, Street TT, Williams FW, Hammond MH, Gottuk DT, Wright MT, Wong JT (2003) Early warning fire detection system using a probabilistic neural network. Fire Technol 39(2):147-171

15. Santolin A, Cavazzini G, Ardizzon G, Pavesi G (2009) Numerical investigation of the interaction between jet and bucket in a Pelton turbine. Proc IME J Power Energ 223(A6):721-728

16. United States (2001) Patent 6,305,620 B1, Patented Oct.23

17. United States (2007) Patent 7,191,964 B2, Patented Mar.20

18. United States (2010) Patent 7,644,777 B2, Patented Jan.12

19. Wang HH, Fan WC (1997) Progress and problems of fire protection in China. Fire Saf J 28(3):191-205

20. Yan HJ, Bai G, He JQ, Li YJ (2010) Model of droplet dynamics and evaporation for sprinkler irrigation. Biosyst Eng 106(4):440 447

21. Yang FC, Shiah SW, Heh TY (2009) The effect of orifice lead cutting edge distance and fluid viscosity on jet performance in high-velocity waterjet cutting systems. Int $\mathrm{J}$ Adv Manufact Technol 40(3):332-341

22. Yang LZ, Zhou XD, Deng ZH, Fan WC, Wang QA (2002) Fire situation and fire characteristic analysis based on fire statistics of China. Fire Saf J 37(8):785-802

23. Zhang Z (2007) Flow interactions in Pelton turbines and the hydraulic efficiency of the turbine system. Proc IME J Power Energ 221(A3):343-358

24. Zhang Z (2009) Inlet flow conditions and the jet impact work in a Pelton turbine. Proc IME J Power Energ 223(A5):589-596

25. Zhang Z (2009) Flow dynamics of the free surface flow in the rotating buckets of a Pelton turbine. Proc IME J Power Energ 223 (A5):609-622

26. Zhong MH, Fan WC, Liu TM, Zhang PH, Wei X, Liao GX (2004) China: some key technologies and the future developments of fire safety science. Saf Sci 42(7):627-637 